\title{
Molecular expression of vascular endothelial growth factor, prokineticin receptor-1 and other biomarkers in infiltrating canalicular carcinoma of the breast
}

\author{
ANGÉLICA MORALES ${ }^{1}$, SUMIKO MORIMOTO ${ }^{1}$, FELIPE VILCHIS ${ }^{1}$, NATSUKO TANIYAMA ${ }^{1}$, \\ CLAUDIA J. BAUTISTA ${ }^{1}$, CARLOS ROBLES ${ }^{2}$ and ENRIQUE BARGALLÓ ${ }^{2}$ \\ ${ }^{1}$ Department of Reproductive Biology, National Institute of Medical Sciences and Nutrition Salvador Zubirán; \\ ${ }^{2}$ Department of Mammary Tumors, National Cancer Institute, Mexico City 14080, Mexico
}

Received November 3, 2015; Accepted June 10, 2016

DOI: $10.3892 / 01.2016 .4961$

\begin{abstract}
Vascular endothelial growth factor (VEGF) is important in the growth and metastasis of cancer cells. In 2001, another angiogenic factor, endocrine gland-derived VEGF (EG-VEGF), was characterized and sequenced. EG-VEGF activity appears to be restricted to endothelial cells derived from endocrine glands. At the molecular level, its expression is regulated by hypoxia and steroid hormones. Although VEGF and EG-VEGF are structurally different, they function in a coordinated fashion. Since the majority of mammary tumors are hormone-dependent, it was hypothesized that EG-VEGF would be expressed in these tumors, and therefore, represent a potential target for anti-angiogenic therapy. The aim of the present study was to assess the expression of VEGF, EG-VEGF and its receptor (prokineticin receptor-1), as well as that of breast cancer resistant protein, estrogen receptor, progesterone receptor and human epidermal growth factor receptor 2 , in 50 breast samples of infiltrating canalicular carcinoma (ICC) and their correlation with tumor staging. The samples were analyzed using reverse transcription-quantitative polymerase chain reaction and immunohistochemistry. Both angiogenic growth factors were identified in all samples. However, in $90 \%$ of the samples, the expression level of VEGF was significantly higher than that of EG-VEGF $(\mathrm{P}=0.024)$. There was no association between the expression of VEGF, EG-VEGF or its receptor with tumor stage. In ICC, the predominant angiogenic factor expressed was VEGF. The expression level of either factor was
\end{abstract}

Correspondence to: Dr Angélica Morales, Department of Reproductive Biology, National Institute of Medical Sciences and Nutrition Salvador Zubirán, Avenue Vasco de Quiroga 15 Col, Belisario Domínguez, Section XVI, Tlalpan, Mexico City 14080, Mexico

E-mail: angelica170969@aol.com

Key words: breast carcinoma, vascular endothelial growth factor, endocrine gland-derived vascular endothelial growth factor, prokineticin receptor-1 not correlated with the tumor-node-metastasis stage. Although ICC is derived from endothelial cells, EG-VEGF expression was not the predominant angiogenic/growth factor in ICC.

\section{Introduction}

Tumor neovascularization is a complex process that plays a crucial role in the development of several types of cancer. The mechanism of hematogenous metastasis requires newly formed capillaries and overexpression of $\geq 1$ positive regulators of angiogenesis such as vascular endothelial growth factor (VEGF) $(1,2)$. Previous studies reported the existence of another angiogenic mitogen called endocrine gland-derived VEGF (EG-VEGF), which selectively acts on the endothelium of endocrine gland cells (3-5). Both angiogenic proteins have been identified in a variety of tissues, and are overexpressed in various cancers (6-12). Every year, $>1,000,000$ women are diagnosed with breast cancer, which is the first cause of mortality in females (13). In the USA, the incidence has been estimated at $12.3 \%$, and in Mexico, at $11.34 \%$, according to the National Cancer Institute of Mexico $(13,14)$. Since breast carcinoma may be asymptomatic and clinically undetectable, numerous women are diagnosed with distant metastasis to the liver, lungs, bones and brain, according to the American Cancer Society (http://www.cancer.org), Centers for Disease Control and Prevention (http://www.cdc.gov/cancer/breast/statistics) and CancerResearchUK(http://www.cancerresearchuk.org/cancer-stat istics/statistics) (15-17). The expression of estrogen receptors (ERs), progesterone receptors (PRs) and human epidermal growth factor receptor 2 (HER-2/neu) are among the most prominent predictive and prognostic factors in breast cancer. Chemotherapy is the main treatment modality (17); however, resistance to drugs is inherent in certain cases and acquired during treatment in others (18). The resistance of malignant cells is often the result of the overexpression of specific members of the adenosine triphosphate-binding cassette family of transporters, which actively export cytotoxic drugs out of the tumor cell, thus preventing cell death (18). One of the members of this family is breast cancer resistance protein (BCRP) $(19,20)$. The mechanisms of BCRP 
regulation involve diverse factors such as hypoxia and steroid hormones (21-23).

The messenger RNA (mRNA) and/or protein expression of BCRP has been detected in numerous types of human cancer, including pancreatic, gastric, renal, hepatocellular, endometrial and colon carcinoma, as well as melanoma and leukemia (24). In addition, its overexpression has been observed in placental choriocarcinoma (BeWo) (25) and human breast cancer (MCF-7) cell lines (26). The aim of the present study was to assess whether the expression of the angiogenic factors VEGF, EG-VEGF and its receptor [prokineticin receptor-1 (PROKR1)] in breast samples of infiltrating canalicular carcinoma (ICC) correlated with tumor staging and could be used as prognosis factors.

\section{Materials and methods}

Reagents. TRIzol reagent was acquired from Ambion (Thermo Fisher Scientific, Inc., Waltham, MA, USA), while Dulbecco's modified Eagle's medium-high glucose (DMEM-HG) culture medium, fetal bovine serum (FBS), oligonucleotides, molecular probes and secondary antibodies were obtained from Invitrogen (Thermo Fisher Scientific, Inc.). TaqMan ${ }^{\circledR}$ Reverse Transcription kit, TaqMan ${ }^{\circledR}$ Universal PCR Master Mix and $\operatorname{TaqMan}^{\circledR}$ probes were purchased from Applied Biosystems (Thermo Fisher Scientific, Inc.). Capillaries were obtained from Roche Applied Science (Pleasanton, CA, USA) and primary antibodies from Santa Cruz Biotechnology, Inc. (Dallas, TX, USA) and Sigma Aldrich (St. Louis, MO, USA). Paraformaldehyde, 4'-6-diamidino-2-phenylindole dihydrochloride (DAPI), ProLong ${ }^{\circledR}$ Gold antifade reagent and phosphate-buffered saline (PBS) were acquired from Sigma-Aldrich.

Patients and tissue collection. Breast carcinomas from 50 patients treated at the Department of Mammary Tumors, National Cancer Institute (Mexico City, Mexico) were analyzed. Ethical approval for the present study protocol was obtained from the Human Research Ethics Committee of the National Cancer Institute. Written informed consent was obtained from all subjects prior to tissue collection, and the study was conducted in accordance with the guidelines stipulated in the Declaration of Helsinki. Breast carcinoma $(n=50)$ full-thickness biopsies were obtained during diagnostic procedures between October 2008 and October 2010. A portion of each harvested tissue sample was immediately frozen to $-75^{\circ} \mathrm{C}$ in liquid $\mathrm{N}_{2}$ to await RNA extraction. The remaining tissue was either fixed in $4 \%$ paraformaldehyde and analyzed by immunohistochemistry (IHC), or placed in DMEM-HG supplemented with $10 \% \mathrm{FBS}, 250 \mathrm{mg} / \mathrm{l}$ penicillin, $50 \mathrm{mg} / \mathrm{l}$ streptomycin and $10^{-9} \mathrm{M}$ estradiol $\left(\mathrm{E}_{2}\right)$ (Steraloids, Inc., Wilton, NH, USA), and transported to the Department of Reproductive Biology, National Institute of Medical Sciences and Nutrition Salvador Zubirán (Mexico City, Mexcio) for in vitro culture. Patient information was obtained from clinical charts, including age, size of tumors, clinical presentation, family history and reproductive factors.

Histology. For all patients, paraffin slides were used for typing and grading the tumor. Histological grading was performed according to the Scarff-Bloom-Richardson (SBR) histologic grading system, which recommends the sum of individual scores for three variables: i) Percentage of tubule differentiation; ii) degree of nuclear pleomorphism; and iii) mitotic count within a defined field area (27). From the total of samples, 28 were classified as SBR grade 8, 9 as SBR grade 6 and 22 as SBR grade 7.

Primer design. Specific oligonucleotide primers for human VEGF, EG-VEGF, PROKR1 and BCRP were designed based on published sequences (Table I). To avoid false positives due to the amplification of contaminating genomic DNA in the complementary DNA (cDNA) preparation, all primers were designed to anneal to exons separated by an intron. Hence, the primers generated short amplicons (65-100 bp) that crossed an intron/exon boundary within the PCR fragment. The VEGF, EG-VEGF, PROKR1 and BCRP amplicons spanned the boundary of exons 7,1,2 and 16, respectively. The primers for glyceraldehyde-3-phosphate dehydrogenase (GAPDH), which served as control, amplified a region between exons 2 and 3 .

Total RNA isolation and $q P C R$ analysis. Total RNA was isolated from breast tissue using TRIzol reagent according to the manufacturer's protocol. The quantity and quality of RNA was determined by measuring the optical density (OD) at $260 \mathrm{~nm}$. The OD260/OD280 ratio of all RNA samples was determined to be between 1.7 and 2.0, indicating that the samples were exceptionally pure. RNA integrity was examined using $1.5 \%$ agarose gel electrophoresis with ethidium bromide staining (data not shown). Single-strand cDNA was synthesized from 3.0 $\mu \mathrm{g}$ purified total RNA using TaqMan ${ }^{\circledR}$ Reverse Transcription kit in a reaction volume of $22 \mu \mathrm{l}$. RT-qPCR was performed using TaqMan ${ }^{\circledR}$ Universal PCR Master Mix and in a LightCycler $^{\circledR} 2.0$ instrument (Roche Diagnostics GmbH, Mannheim, Germany). Each reaction mixture included $10 \mu \mathrm{l} 2 \mathrm{X}$ TaqMan $^{\circledR}$ Universal PCR Master Mix, 5.2 $\mu$ l sterile EMD Millipore water (Billerica, MA, USA), $0.1 \mu$ l forward primer (20 nM), $0.1 \mu \mathrm{l}$ reverse primer $(20 \mathrm{nM}), 0.1 \mu 1$ TaqMan ${ }^{\circledR}$ probe $(10 \mathrm{nM})$ and $2.5 \mu \mathrm{l}$ RT products. The PCR cycling conditions included denaturation at $95^{\circ} \mathrm{C}$ for $10 \mathrm{~min}$, followed by 40 cycles of $95^{\circ} \mathrm{C}$ for $10 \mathrm{sec}$, annealing at $60^{\circ} \mathrm{C}$ for $30 \mathrm{sec}$, and extension at $72^{\circ} \mathrm{C}$ for $10 \mathrm{sec}$. The sizes of the resulting amplicons were 84,88 , 62,94 and $66 \mathrm{bp}$, and the probes utilized were numbered 63, 22, 45, 12 and 60, respectively, in the Universal ProbeLibrary (Roche Diagnostics $\mathrm{GmbH}$ ). All studies were performed at least in duplicate. Quantification of relative mRNA levels was conducted by determining the threshold cycle $(\mathrm{Cq})$, which is defined as the cycle at which the fluorescence emission intensity of the 6-carboxyfluorescein reporter exceeds the standard deviation of the mean baseline emission intensity for cycles 3 to 10 by a factor of 10 (25). Normalization of the cDNA load was performed against the housekeeping gene GAPDH according to the following formula: Cq (VEGF, EG-VEGF, PROKR1 or BCRP $)-\mathrm{Cq}(\mathrm{GAPDH})=\Delta \mathrm{Cq}$.

$I H C$. Serial sections $(5-\mu \mathrm{m}$ thick) were prepared from paraffin-embedded tissues, and the sections were deparaffinized in xylene and then rehydrated through decreasing concentrations of ethanol. Antigen retrieval was performed by treating the sections for $10 \mathrm{~min}$ in a $0.01 \mathrm{M}$ citrate buffer, and endogenous peroxidase activity was quenched with $10 \%$ 
Table I. Primers used in the present study.

Gene

Sequence

VEGF

(GenBank accession No. NM_001025366)

Forward: 5'-GCAGCTTGAGTTAAACGAACG-3' Reverse: 5'-GGTTCCCGAAACCCTGAG-3'

EG-VEGF

(GenBank accession No.NM_32414)

Forward: 5'-CCACGCGAGTCTCAATCA-3'

Reverse: 5'-ACTGGACATCCCGCTCAC-3'

PROKR1

(GenBank accession No. NM_138964)

Forward: 5'-ACCTGCGCACTGTCTCTCTC-3' Reverse: 5'-CTCAGCGGATGGACAATAGC-3'

BCRP

(GenBank accession No. NM_004827)

Forward: 5'-ATTTGGTAAAGCAGGGCATCC-3'

Reverse: 5'-CAAGGCCACGTGATTCTT-3'

GAPDH

(GenBank accession No. NM_002046)

Forward: 5'-AGCCACATCGCTGAGACAC-3' Reverse: 5'-GCCCAATACGACCAAATCC-3'

VEGF, vascular endothelial growth factor; EG-VEGF, endocrine gland-derived vascular endothelial growth factor; PROKR1, prokineticin receptor-1; BCRP, breast cancer resistant protein; GAPDH, glyceraldehyde-3-phosphate dehydrogenase.

Table II. Antibodies and spectral characteristics of rhodamine, Alexa Fluor ${ }^{\circledR}$ 532, Alexa Fluor ${ }^{\circledR}$ 647, FITC and DAPI dyes.

\begin{tabular}{llllrr}
\hline Primary antibody/dye & Secondary dye & Color & Abs $^{\mathrm{a}}$ & Em $^{\mathrm{a}}$ & Extinction coefficient $^{\mathrm{b}}$ \\
\hline Anti-EG-VEGF & Rhodamine & Red & 550 & 600 & 91,000 \\
Anti-PROKR1 & Alexa Fluor $^{\circledR} 532$ & Yellow & 532 & $553^{\mathrm{c}}$ & 81,000 \\
Anti-HER-2/neu & Alexa Fluor & \\
Anti-cytokeratin-7 & FITC & Pink & 650 & $665^{\mathrm{c}}$ & 239,000 \\
DAPI & Nucleus counterstaining & Green & 494 & 518 & $>70,000$ \\
\hline
\end{tabular}

${ }^{\mathrm{a}}$ Maximum absorbance and fluorescence emission wavelengths in $\mathrm{nm} .{ }^{\mathrm{b}}$ Extinction coefficient at $\lambda \mathrm{max}$ in $\mathrm{cm}^{-1} \mathrm{M}^{-1}$. ${ }^{\mathrm{c}}$ Human vision is insensitive to light beyond $\sim 650 \mathrm{~nm}$ (www.probes.com); therefore, it is not possible to visualize far red fluorescent dyes by looking through the eyepiece of a conventional fluorescence microscope (28). FITC, fluorescein isothiocyanate; DAPI, 4'-6-diamidino-2-phenylindole dihydrochloride; Abs, absorbance; Em, emission; EG-VEGF, endocrine gland-derived vascular endothelial growth factor; PROKR1, prokineticin receptor-1; HER-2/neu, human epidermal growth factor receptor 2.

(vol/vol) $\mathrm{H}_{2} \mathrm{O}_{2}$ /methanol at room temperature. To prevent the nonspecific binding of antibodies, the sections were preincubated with protein blocking buffer diluted in PBS/bovine serum albumin (BSA; 1\%; Sigma-Aldrich) for $1 \mathrm{~h}$ prior to overnight incubation at $4^{\circ} \mathrm{C}$ with the corresponding primary antibody. Anti-EG-VEGF (A-12; sc-30343; dilution, 1:300), anti-PROKR1 (HPA029396; dilution, 1:300), anti-HER-2/neu (C-18; sc-284; dilution, 1:100) and anti-cytokeratin-7 (5F282; sc-70936; dilution, 1:100) were used. The slides were washed three times for $5 \mathrm{~min}$ in PBS. Antibody binding was visualized with anti-goat-immunoglobulin G ( $\operatorname{IgG}$ )-rhodamine (sc-3945), anti-rabbit-IgG-Alexa Fluor ${ }^{\circledR} 532$ (A11009), anti-rabbit-IgG-Alexa Fluor ${ }^{\circledR} 647$ (A31573) and anti-mouse-fluorescein isothiocyanate (sc-2010) secondary antibodies at $1: 200$ dilution at $4^{\circ} \mathrm{C}$ for $2 \mathrm{~h}$. Subsequently, the sections were washed and mounted with ProLong ${ }^{\circledR}$ Gold antifade reagent prior to be visualized and photographed using a confocal laser scanning microscope (TCS SP5; Leica Microsystems, Inc., Buffalo Grove, IL, USA). In each case, negative controls without the primary antibody were included (data not shown).

EG-VEGF, HER-2/neu and cytokeratin-7 in cell culture. A total of 10 random samples of breast cancer of various degrees were obtained in order to study cultured cells on glass chamber slides (Nalge Nunc International; Thermo Fisher Scientific, Inc.). The cells were maintained in monolayer culture in DMEM-HG supplemented with 10\% FBS, $250 \mathrm{mg} / 1$ penicillin, $50 \mathrm{mg} / 1$ streptomycin and $10^{-9} \mathrm{M} \mathrm{E}_{2}$. The cultures were incubated at $37^{\circ} \mathrm{C}$ in a $5 \% \mathrm{CO}_{2}$ humidified incubator, and fresh medium was provided every other day. The cells were washed twice with PBS and fixed in $4 \%$ paraformaldehyde in PBS for $10 \mathrm{~min}$, followed by a PBS wash and subsequent treatment with $50 \mathrm{mM}$ ammonium chloride in PBS for $10 \mathrm{~min}$ 
to reduce the auto-fluorescence of aldehyde groups during immunofluorescence microscopy. The cells were then washed again with PBS and incubated in permeabilization buffer $(0.2 \%$ Triton X-100 in PBS) for $5 \mathrm{~min}$. To prevent the nonspecific binding of antibodies, the cells were incubated with blocking buffer containing $10 \% \mathrm{BSA}$ diluted in PBS for $30 \mathrm{~min}$ at room temperature. Next, the slides were incubated overnight at $4^{\circ} \mathrm{C}$ with antibodies against EG-VEGF (gland-derived endothelial cell marker), HER-2/neu (oncoprotein) and cytokeratin-7 (epithelial tumor marker) at the aforementioned dilutions.

Following three washes for $5 \mathrm{~min}$ each, the slides were incubated with the corresponding secondary antibody at 1:200 dilution at $25^{\circ} \mathrm{C}$ for $2 \mathrm{~h}$. The sections were then washed, the nuclei were counterstained with DAPI, and coverslips were attached. Digitized images of the same microscopic field were captured using four specific band-pass filters. The wavelength of the emitted light are shown in Table II. Images were obtained using a TCS-SP5 confocal laser scanning microscope with $20 \mathrm{X}$ and 40X objectives, 1.4 oil immersion lens, and identical exposure times. Simultaneous evaluation of the negative control (without primary antibody) confirmed the absence of nonspecific immunofluorescent staining, cross-immunostaining or fluorescence bleed-through. Representative photomicrographs were processed using Adobe Photoshop (version CS6; Adobe Systems, Inc., San Jose, CA, USA) without any further adjustment to maintain the veracity of the findings.

\section{Results}

Although breast cancer is a heterogeneous disease, the present study was conducted exclusively with the ICC histologic phenotype (17). In accordance with SBR scoring, there were 22 samples (44\%) of grade $6 / 7$ and $28(56 \%)$ of grade $8 / 9$. The patients had a mean age of 53.4 years (ranging from 26 to 86 years), and no significant differences were noticed when comparing this parameter with tumor size. A family history of breast cancer was recorded for 4 patients, and a history of relatives with cancer at other sites was recorded for 10 patients. Clinical staging criteria were based on the tumor-node-metastasis (TNM) system, which considers the size of the tumor (T), lymph nodes (N) and metastases (M) (17). The size of the majority of tumors (32 samples, 64\%) was classified as T2/T3, being $>20$ and $\leq 50 \mathrm{~mm}$, while in 16 samples $(32 \%)$, it was graded as T4. There were 34 patients $(68 \%)$ presenting infiltrated ipsilateral lymph nodes.

Regarding metastasis, 17 patients (34\%) were positive and $33(66 \%)$ negative, according to the computed tomography scan. Additional data were obtained, including the status of the receptors for steroid hormones and two oncogenic markers (Table III). Molecular studies conducted on the mRNA expression of EG-VEGF and PROKR1 exhibited variable results. Whereas low levels of EG-VEGF were identified in 28 samples, this protein was undetectable in 22 samples. Although PROKR1 is required for EG-VEGF to exert its function, the mRNA of this receptor was only detectable in 17 samples, 14 of which were positive for EG-VEGF. To confirm the expression of both proteins, IHC studies were conducted in tumoral tissue and cell culture. EG-VEGF and PROKR1 were localized in the cytoplasm (Fig. 1A and C, respectively). Additionally, the expression of cytokeratin-7
Table III. Clinical and histological data.

\begin{tabular}{|c|c|}
\hline Characteristics & No. of patients $(\%)$ \\
\hline Total no. of patients & $50(100)$ \\
\hline Mean age, years (range) & $53.4(26-86)$ \\
\hline Mean tumor size, mm (range) & $20(2-12)$ \\
\hline \multicolumn{2}{|l|}{ Menopausal status } \\
\hline Pre & $7(14)$ \\
\hline Post & $43(86)$ \\
\hline Histology, ICC & $50(100)$ \\
\hline \multicolumn{2}{|l|}{ TNM stage } \\
\hline \multicolumn{2}{|l|}{ Tumor size } \\
\hline pT1 & 2 \\
\hline pT2 & 20 \\
\hline pT3 & 12 \\
\hline pT4 & 16 \\
\hline \multicolumn{2}{|l|}{ Nodal status } \\
\hline $\mathrm{pN} 0$ & 8 \\
\hline $\mathrm{pN} 1$ & 16 \\
\hline $\mathrm{pN} 2$ & 18 \\
\hline $\mathrm{pN} 3$ & 8 \\
\hline \multicolumn{2}{|l|}{ Metastatic status } \\
\hline pM0 & 33 \\
\hline pM1 & 17 \\
\hline \multicolumn{2}{|l|}{ Hormone receptor status } \\
\hline Positive ER & 6 \\
\hline Positive PR & 1 \\
\hline Positive ER and PR & 18 \\
\hline Positive HER-2/neu & 5 \\
\hline Negative ER, PR and HER-2/neu & 11 \\
\hline Positive ER and HER-2/neu & 3 \\
\hline Positive PR and HER-2/neu & 2 \\
\hline Positive ER, PR and HER-2/neu & 4 \\
\hline
\end{tabular}

ICC, infiltrating canalicular carcinoma; TNM, tumor-node-metastasis; ER estrogen receptor; PR, progesterone receptor; HER-2/neu, human epidermal growth factor receptor 2 .

(Fig. 1B) and HER-2/neu (Fig. 1D) was analyzed, since cytokeratin-7 expression is considered particularly useful for the diagnosis of poorly differentiated tumors (29). In cultures of several randomly selected samples that were grown to $80 \%$ confluence, positive immunostaining of EG-VEGF, HER-2/neu and cytokeratin-7 was co-localized (Fig. 2).

\section{Discussion}

In the normal human breast, two cell types have been morphologically described, inner luminal cells (parenchyma) and outer myoepithelial cells (stroma) (30). This anatomical distinction is important for understanding the interactions between both cell types during breast tumorigenesis. The majority of breast malignancies (>95\%) are derived from an epithelial lineage (31). The epithelial-mesenchymal interactions and the tissue-specific microenvironment modulate the growth, progression and 

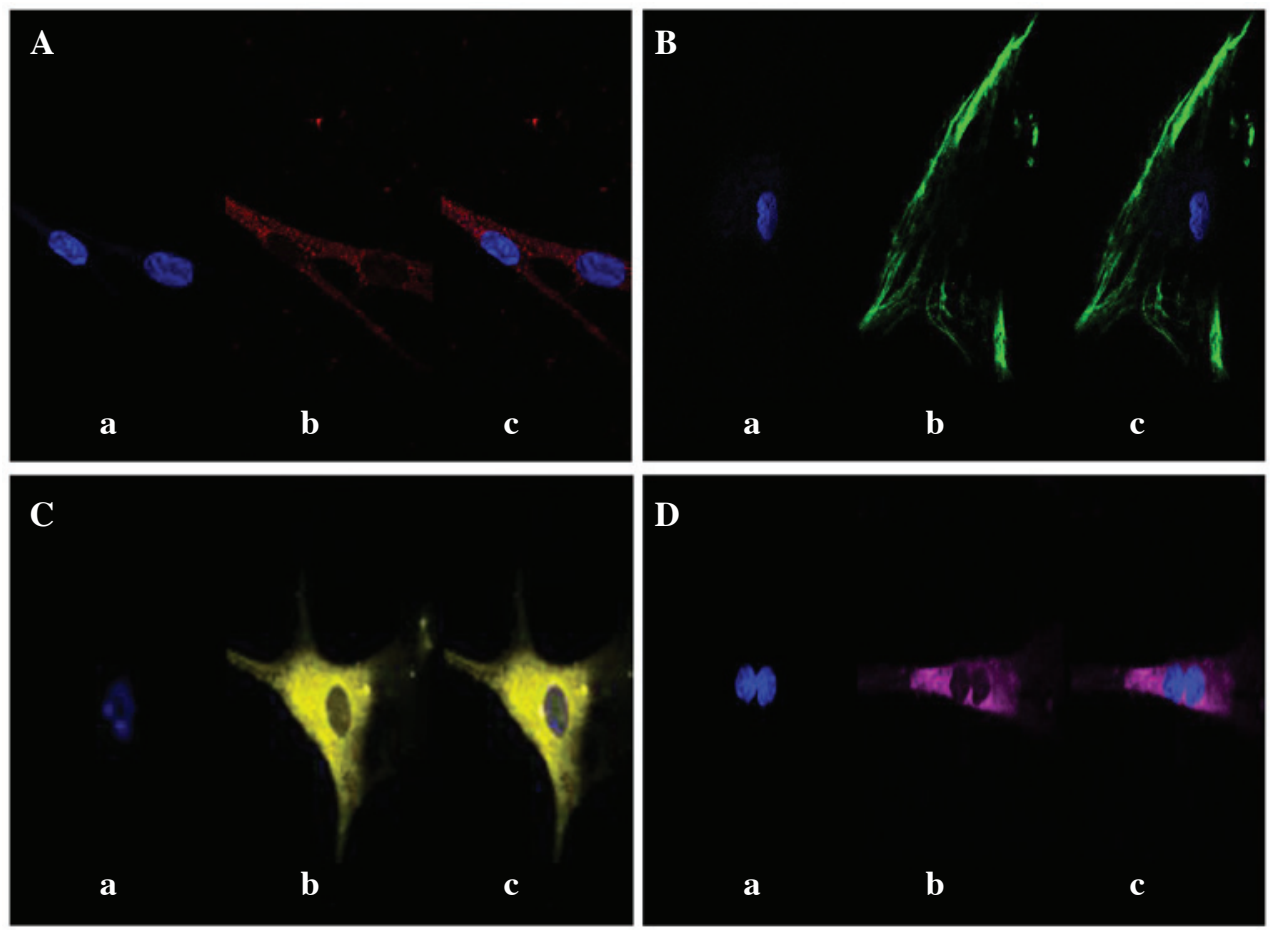

Figure 1. Representative photomicrographs of monolayer-cultured cells. Images were obtained using band-pass filters specific for a) 4'-6-diamidino-2-phenylindole dihydrochloride (blue labeling), b) specific fluorophore and c) co-localization of both fluorophores. Positive staining for (A) endocrine gland-derived vascular endothelial growth factor (red), (B) cytokeratin-7 (green), (C) prokineticin receptor-1 (yellow) and (D) human epidermal growth factor receptor 2 (pink). Magnification, $\mathrm{x} 100$.

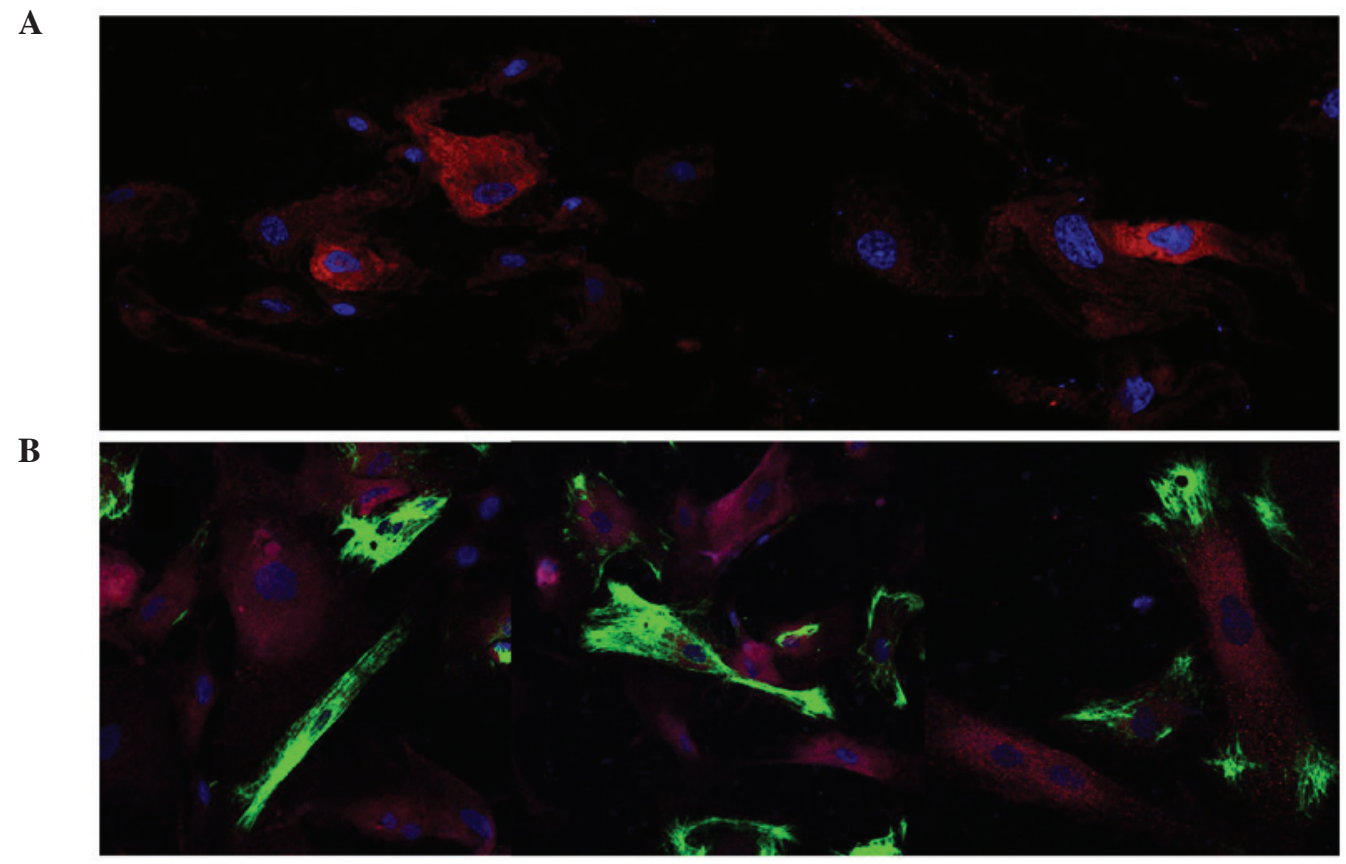

Figure 2. (A) Representative photomicrographs of breast carcinoma cells exhibiting immunofluorescence staining for EG-VEGF (red). (B) Co-localization of EG-VEGF (red staining), human epidermal growth factor receptor 2 (pink staining) and cytokeratin-7 (green staining). The images were acquired using band-pass filters for rhodamine, Alexa Fluor ${ }^{\circledR} 647$ and fluorescein isothiocyanate. The nuclei were stained with blue-fluorescent 4'-6-diamidino-2-phenylindole dihydrochloride. EG-VEGF, endocrine gland-derived vascular endothelial growth factor.

metastatic behavior of cancer cells (31). The expression levels of several biomarkers, including ERs, PRs and HER-2/neu, play a critical role in the therapy and prognosis of breast tumors (17).

Previous reports on human breast cancer cell lines, patient tumor samples and clinical studies have all indicated that progesterone is a risk factor for breast cancer, and that changes in progesterone signaling pathways contribute to the early stage of tumor progression $(22,25)$. PR signaling stimulates epithelial cell proliferation via an unknown mechanism in pre-neoplastic lesions and mammary tumors (32). However, 
primary tumors with negative PR expression have been associated with a less differentiated, more invasive phenotype and a worse prognosis than those expressing PR (32). The data from the current study differs from the aforementioned previous evidence in the aggressiveness of PR-negative tumors. Of 25 such tumors analyzed in the present study, only 10 were poorly differentiated and 7 had an invasive phenotype. In addition, of the 31 ER-positive tumors identified in the present study, only 18 were moderately differentiated.

The HER-2/neu oncogene is amplified/overexpressed in $15-30 \%$ of breast cancers (17). This overexpression/amplification of the HER-2/neu protein appears to be of importance for the therapeutic benefit of anthracycline-based treatments, and it is the target for trastuzumab (Herceptin ${ }^{\circledR}$ ), a humanized monoclonal antibody designed as a therapy for metastatic breast cancer (33). The absence of ER, PR and HER-2/neu is defined as triple negative breast cancer (TNBC), which is regarded as an aggressive disease that affects young patients, and is characterized by early relapse, particular visceral metastasis and poor prognosis (34). In the current study, 11 patients $(22 \%)$ were TNBC, of which, 3 were young women ( $<40$ years of age), and 4 developed metastatic tumors. This percentage is similar to that reported in previous studies (35). However, other studies have suggested that Hispanic women are more likely to present TNBC than Caucasian women (36). In 2009, Linderholm et al reported higher levels of VEGF in TNBC than non-TNBC patients (37). The present study obtained similar results, finding that all TNBC patients exhibited slightly greater VEGF expression than non-TNBC patients. Regarding the two angiogenic proteins assessed in the current study, VEGF was expressed at a significantly higher level than EG-VEGF. To the best of our knowledge, the present study is the first to report the expression of EG-VEGF in mammary gland tumors. A previous study demonstrated the expression of this protein in a wide variety of human tissues, but did not include the mammary gland (38).

Breast cancer is a heterogeneous disease that presents different biological patterns and histologically diverse subtypes (17). The development of resistance to multiple chemotherapeutic drugs suggests the involvement of BCRP during the treatment of numerous breast carcinomas (18). Unexpectedly, the expression of BCRP was detected in all tumors, independently of TNM and the expression of steroid receptors. In 2011, Moitra et al explained that the BCRP phenotype can be produced by an extensive population of tumor cells, cancer stem cells, cells with acquired resistance in chemotherapy and cells with induced genetic changes (39). Large progress has been made in recent years in countering BCRP-induced drug resistance, and 20 molecules and 6 steroids have been identified that can inhibit BCRP activity $(18,40-42)$. The level of expression of BCRP and the treatment outcome in the present series deserves further analysis.

The differential expression of the angiogenic factors evaluated in the present study could be attributed to the cancer molecular subtype, which is based on gene expression profiles. Recent research has indicated that human breast cells can exhibit extensive lineage plasticity (43), which may explain why marker profiles have been difficult to associate with distinct tumors subtypes. In 2014, Santagata et al analyzed normal breast cells and identified 11 cell subtypes in the luminal layer; in the case of breast tumors, none of them exhibited a purely basal-like phenotype (30).

The present IHC data from human breast cancer biopsies indicate that only certain cells were positively stained for EG-VEGF and PROKR1, while others exhibited abundant staining for cytokeratin-7 and HER-2/neu.

Several antineoplastic therapies are aiming to block the function of VEGF (44). However, in the majority of cases, tumors produce a large number of other angiogenic factors, indicating that angiogenesis is a complex process involving multiple signaling pathways (45). Over the last two decades, researchers around the world have developed new techniques involving drugs that target VEGF, including aflibercept and metronomic chemotherapy (46). Aflibercept binds to and inhibits all isoforms of VEGF, and also binds to placental growth factor. Metronomic chemotherapy blocks proliferating tumor cells (47) and is important in breast cancer metastasis (48). Bergers and Hanahan (46) and Dempke and Heinemann (44) reported the results of preclinical studies indicating that certain mechanisms of tumor adaptation and resistance are based on increased tolerance to hypoxia, which leads to a decreased dependence on neovascularization. The role of hormones in the regulation of VEGF is controversial. Numerous studies on estrogen and progesterone have demonstrated that both are able to increase VEGF mRNA and/or protein expression $(49,50)$. In contrast, other studies do not support these findings (51-53).

The regulation of VEGF expression and function by steroid hormones may act through distinct mechanisms in the various cells types involved in breast cancer. Further studies are required to elucidate the mechanism through which EG-VEGF expression is reduced or absent relative to the expression of VEGF in steroid hormone-dependent tumors. These factors could conceivably be used as alternative targets to modulate angiogenesis. The development of novel therapeutic drugs, anti-angiogenic molecules, hormonal agents and biomarkers is important for a better understanding of the molecular mechanisms involved in breast cancer. Successful treatment of patients may depend on addressing the combination of individual genotypes and alternative targets to modulate angiogenesis and reduce drug resistance to chemotherapy.

\section{Acknowledgements}

The authors would like to thank the staff in the operating room (Department of Mammary Tumors, National Cancer Institute, Mexico City, Mexico) for their assistance in the procurement of tissue samples, as well as Ms. Veronica Rodriguez of the Histopathology Facility Faculty of Medicine and Dr Silvia Reyes Maya of the Faculty of Medicine (both of the National Autonomous University of Mexico) for her technical assistance with immunofluorescence confocal microscopy.

\section{References}

1. Nishida N, Yano H, Nishida T, Kamura T and Kojiro M: Angiogenesis in cancer. Vasc Health Risk Manag 2: 213-219, 2006.

2. Schneider BP and Miller KD: Angiogenesis of breast cancer. J Clin Oncol 23: 1782-1790, 2005. 
3. LeCouter J, Lin R and Ferrara N: The role of EG-VEGF in the regulation of angiogenesis in endocrine glands. Cold Spring Harb Symp Quant Biol 67: 217-221, 2002.

4. Kaser A, Winklmayr M, Lepperdinger G and Kreil G: The AVIT protein family. Secreted cysteine-rich vertebrate proteins with diverse functions. EMBO Rep 4: 469-473, 2003.

5. Zhou QY and Meidan R: Biological function of prokineticins. Results Probl Cell Differ 46: 181-199, 2008.

6. Keramidas M, Faudot C, Cibiel A, Feige JJ and Thomas M: Mitogenic functions of endocrine gland-derived vascular endothelial growth factor and Bombina variegata 8 on steroidogenic adrenocortical cells. J Endocrinol 196: 473-482, 2008.

7. Kisliouk T, Levy N, Hurwitz A and Meidan R: Presence and regulation of endocrine gland vascular endothelial growth factor/prokineticin-1 and its receptors in ovarian cells. J Clin Endocrinol Metab 88: 3700-3707, 2003.

8. Fraser HM, Bell J, Wilson $\mathrm{H}$, Taylor PD, Morgan K, Anderson RA and Duncan WC: Localization and quantification of cyclic changes in the expression of endocrine gland vascular endothelial growth factor in the human corpus luteum. J Clin Endocrinol Metab 90: 427-434, 2005.

9. Morales A, Morimoto S, Díaz L, Robles G and Díaz-Sánchez V: Endocrine gland-derived vascular endothelial growth factor in rat pancreas: Genetic expression and testosterone regulation. J Endocrinol 197: 309-314, 2008.

10. Nagano H, Goi T, Koneri K, Hirono Y, Katayama K and Yamaguchi A: Endocrine gland-derived vascular endothelia growth factor (EG-VEGF) expression in colorectal cancer. J Surg Oncol 96: 605-610, 2007.

11. Perrot-Applanat M and Di Benedetto M: Autocrine functions of VEGF in breast tumor cells: Adhesion, survival, migration and invasion. Cell Adh Migr 6: 547-553, 2012.

12. Kassim SK, El-Salahy EM, Fayed ST, Helal SA, Helal T, Azzam Eel-D and Khalifa A: Vascular endothelial growth factor and interleukin-8 are associated with poor prognosis in epithelial ovarian cancer patients. Clin Biochem 37: 363-369, 2004.

13. DeSantis CE, Bray F, Ferlay J, Lortet-Tieulent J, Anderson BO and Jemal A: International variation in female breast cancer incidence and mortality rates. Cancer Epidemiol Biomarkers Prev 24: 1495-1506, 2015.

14. Córdova JA, Hernández M, Ortiz ME, Lezana MA, López-Gatell $\mathrm{H}$ and Alpuche CM: Epidemiological profile of malignant tumors in Mexico. IEPSA, Mexico City, pp145-195, 2011.

15. Euhus D, Di Carlo PA and Khouri NF: Breast cancer screening. Surg Clin North Am 95: 991-1011, 2015.

16. Kennecke H, Yerushalmi R, Woods R, Cheang MC, Voduc D, Speers $\mathrm{CH}$, Nielsen TO and Gelmon K: Metastatic behavior of breast cancer subtypes. J Clin Oncol 28: 3271-3277, 2010.

17. Li J, Chen Z, Su K and Zeng J: Clinicopathological classification and traditional prognostic indicators of breast cancer. Int J Clin Exp Pathol 8: 8500-8505, 2015.

18. Mao Q and Unadkat JD: Role of the breast cancer resistance protein (BCRP/ABCG2) in drug transport-an update. AAPS J 17: 65-82, 2015.

19. Faneyte IF, Kristel PM, Maliepaard M, Scheffer GL, Scheper RJ, Schellens JH and van de Vijver MJ: Expression of the breast cancer resistance protein in breast cancer. Clin Cancer Res 8: 1068-1074, 2002.

20. Glavinas H, Krajcsi P, Cserepes J and Sarkadi B: The role of $\mathrm{ABC}$ transporters in drug resistance, metabolism and toxicity. Curr Drug Deliv 1: 27-42, 2004.

21. Javam M, Audette MC, Iqbal M, Bloise E, Gibb W and Matthews SG: Effect of oxygen on multidrug resistance in term human placenta. Placenta 35: 324-330, 2014

22. Vore $M$ and Leggas M: Progesterone acts via progesterone receptors $\mathrm{A}$ and $\mathrm{B}$ to regulate breast cancer resistance protein expression. Mol Pharmacol 73: 613-615, 2008.

23. Zhang Y, Wang H, Wei L, Li G, Yu J, Gao Y, Gao P, Zhang X, Wei F, Yin D and Zhou G: Transcriptional modulation of BCRP gene to reverse multidrug resistance by toremifene in breast adenocarcinoma cells. Breast Cancer Res Treat 123: 679-689, 2010.

24. Diestra JE, Scheffer GL, Catala I, Maliepaard M, Schellens JH, Scheper RJ, Germà-Lluch JR and Izquierdo MA: Frequent expression of the multi-drug resistance-associated protein $\mathrm{BCRP} / \mathrm{MXR} / \mathrm{ABCP} / \mathrm{ABCG} 2$ in human tumours detected by the BXP-21 monoclonal antibody in paraffin-embedded material. J Pathol 198: 213-219, 2002.
25. Wang H, Lee EW, Zhou L, Leung PC, Ross DD, Unadkat JD and Mao Q: Progesterone receptor (PR) isoforms PRA and PRB differentially regulate expression of the breast cancer resistance protein in human placental choriocarcinoma BeWo cells. Mo Pharmacol 73: 845-854, 2008.

26. Nakagawa M, Schneider E, Dixon KH, Horton J, Kelley K, Morrow $\mathrm{C}$ and Cowan KH: Reduced intracellular drug accumulation in the absence of P-glycoprotein (mdrl) overexpression in mitoxantrone-resistant human MCF-7 breast cancer cells. Cancer Res 52: 6175-6181, 1992.

27. Schumacher M, Schmoor C, Sauerbrei W, Schauer A, Ummenhofer L, Gatzemeier W and Rauschecker H: The prognostic effect of histological tumor grade in node-negative breast cancer patients. Breast Cancer Res Treat 25: 235-245, 1993.

28. Panchuk-Voloshina N,Haugland RP,Bishop-Stewart J, Bhalgat MK, Millard PJ, Mao F, Leung WY and Haugland RP: Alexa dyes, a series of new fluorescent dyes that yield exceptionally bright, photostable conjugates. J Histochem Cytochem 47: 1179-1188, 1999.

29. Chu P, Wu E and Weiss LM: Cytokeratin 7 and cytokeratin 20 expression in epithelial neoplasms: A survey of 435 cases. Mod Pathol 13: 962-972, 2000.

30. Santagata S, Thakkar A, Ergonul A, Wang B, Woo T, Hu R, Harrell JC, McNamara G, Schwede M, Culhane AC, et al: Taxonomy of breast cancer based on normal cell phenotype predicts outcome. J Clin Invest 124: 859-870, 2014.

31. Howlett AR and Bissell MJ: The influence of tissue microenvironment (stroma and extracellular matrix) on the development and function of mammary epithelium. Epithelial Cell Biol 2: 79-89, 1993.

32. Obr AE and Edwards DP: The biology of progesterone receptor in the normal mammary gland and in breast cancer. Mol Cell Endocrinol 357: 4-17, 2012.

33. Shak S: Overview of the trastuzumab (Herceptin) anti-HER2 monoclonal antibody clinical program in HER2-overexpressing metastatic breast cancer. Herceptin Multinational Investigator Study Group. Semin Oncol 26 (Suppl 12): 71-77, 1999.

34. Schmadeka R, Harmon BE and Singh M: Triple-negative breast carcinoma: Current and emerging concepts. Am J Clin Pathol 141: 462-477, 2014.

35. Perou CM, Sørlie T, Eisen MB, van de Rijn M, Jeffrey SS, Rees CA, Pollack JR, Ross DT, Johnsen H, Akslen LA, et al: Molecular portraits of human breast tumors. Nature 406: 747-752, 2000.

36. Bauer KR, Brown M, Cress RD, Parise CA and Caggiano V: Descriptive analysis of estrogen receptor (ER)-negative, progesterone receptor (PR)-negative and HER2-negative invasive breast cancer, the so-called triple-negative phenotype: A population-based study from the California cancer registry. Cancer 109: 1721-1728. 2007.

37. Linderholm BK, Hellborg H, Johansson U, Elmberger G, Skoog L, Lehtiö J and Lewensohn R: Significantly higher levels of vascular endothelial growth factor (VEGF) and shorter survival times for patients with primary operable triple-negative breast cancer. Ann Oncol 20: 1639-1646, 2009.

38. LeCouter J, Kowalski J, Foster J, Hass P, Zhang Z, Dillard-Telm L, Frantz G, Rangell L, DeGuzman L, Keller GA, et al: Identification of an angiogenic mitogen selective for endocrine gland endothelium. Nature 412: 877-884, 2001

39. Moitra K, Lou H and Dean M: Multidrug efflux pumps and cancer stem cells: Insights into multidrug resistance and therapeutic development. Clin Pharmacol Ther 89: 491-502, 2011.

40. Dankers AC, Sweep FC, Pertijs JC, Verweij V, van den Heuvel JJ, Koenderink JB, Russel FG and Masereeuw R: Localization of breast cancer resistance protein (Bcrp) in endocrine organs and inhibition of its transport activity by steroid hormones. Cell Tissue Res 349: 551-563, 2012.

41. Ee PL, Kamalakaran S, Tonetti D, He X, Ross DD and Beck WT: Identification of a novel estrogen response element in the breast cancer resistance protein (ABCG2) gene. Cancer Res 64: 1247-1251, 2004

42. Imai Y,Ishikawa E, Asada S and Sugimoto Y: Estrogen-mediated post transcriptional down-regulation of breast cancer resistance protein/ABCG2. Cancer Res 65: 596-604, 2005.

43. Roy S, Gascard P, Dumont N, Zhao J, Pan D, Petrie S, Margeta M and Tlsty TD: Rare somatic cells from human breast tissue exhibit extensive lineage plasticity. Proc Natl Acad Sci USA 110: 4598-4603, 2013.

44. Dempke WC and Heinemann V: Resistance to EGF-R (erbB-1) and VEGF-R modulating agents. Eur J Cancer 45: 1117-1128, 2009. 
45. Mercurio AM, Lipscomb EA and Bachelder RE: Non-angiogenic functions of VEGF in breast cancer. J Mammary Gland Biol Neoplasia 10: 283-290, 2005.

46. Bergers $\mathrm{G}$ and Hanahan D: Modes of resistance to anti-angiogenic therapy. Nat Rev Cancer 8: 592-603, 2008.

47. Chan A: Antiangiogenic therapy for metastatic breast cancer: current status and future directions. Drugs 69: 167-181, 2009.

48. Banys-Paluchowski M, Schütz F, Ruckhäberle E, Krawczyk N and Fehm T: Metronomic chemotherapy for metastatic breast cancer - a systematic review of the literature. Geburtshilfe Frauenheilkd 76: 525-534, 2016

49. Ruohola JK, Valve EM, Karkkainen MJ, Joukov V, Alitalo K and Härkönen PL: Vascular endothelial growth factors are differentially regulated by steroid hormones and antiestrogens in breast cancer cells. Mol Cell Endocrinol 149: 29-40, 1999.
50. Takei H, Lee ES and Jordan VC: In vitro regulation of vascular endothelial growth factor by estrogens and antiestrogens in estrogen-receptor positive breast cancer. Breast Cancer 9: 39-42, 2002.

51. Bogin L and Degani H: Hormonal regulation of VEGF in orthotopic MCF7 human breast cancer. Cancer Res 62: 1948-1951, 2002.

52. Mirkin S, Wong BC and Archer DF: Effect of 17 beta-estradiol, progesterone, synthetic progestins, tibolone and tibolone metabolites on vascular endothelial growth factor mRNA in breast cancer cells. Fertil Steril 84: 485-491, 2005.

53. Mirkin S, Wong BC and Archer DF: Effects of 17beta-estradiol, progesterone, synthetic progestins, tibolone and raloxifene on vascular endothelial growth factor and Thrombospondin-1 messenger RNA in breast cancer cells. Int J Gynecol Cancer 16 (Suppl 2): S560-S563, 2006. 